requirements (7)

Such dilemmas are likely to be common in public health research, but the accounts may vary based on the researcher's personal values, training and past experiences. Researchers may, therefore, opt for maintaining a diary of such ethical dilemmas they come across in the field and reflect on the choices and possible consequences of their actions. Further, they should initiate discussion with peers and mentors to facilitate better engagement with such issues. If nothing else, they must recognise that while it may be difficult to endorse such practices, the patient and his family members are probably not diminished in front of the non-formal providers the way they might be when they access a formal provider.

\section{References}

1. Vijayan B. Observation of unsafe medical practice during research in a healthcare-deprived area. Indian J Med Ethics. 2020 Jan-Mar; 5(1) NS: 167. DOI: 10.20529/IJME.2020.012
2. Roy N, Gerdin M, Ghosh S, Gupta A, Kumar V, Khajanchi M, Schneider EB, Gruen R, Tomson G, von Schreeb J. 30-day in-hospital trauma mortality in four urban university hospitals using an Indian trauma registry. World J Surg. 2016 Jun;40(6):1299-307. Doi: 10.1007/s00268-016-3452-y.

3. Sebastian S. Does preoperative scalp shaving result in fewer postoperative wound infections when compared with no scalp shaving? A systematic review. J Neurosci Nurs. 2012 Jun;44(3):149-56. Doi: 10.1097/JNN.0b013e31825106d2.

4. Aasen EM, Dahl BM. Construction of patients' position in Norway's Patients' Rights Act. Nurs Ethics. 2019 Nov-Dec; 26(7-8):2278-2287. doi: 10.1177/0969733018791345. Epub 2018 Aug 23.

5. Fochsen G, Deshpande K, Thorson A.Power imbalance and consumerism in the doctor-patient relationship: health care providers' experiences of patient encounters in a rural district in India. Qual Health Res. 2006 Nov;16(9):1236-51.

6. Markel H."I swear by Apollo"—on taking the Hippocratic Oath. N Engl J Med. 2004 May 13;350(20):2026-9.

7. Surmiak A. Should we maintain or break confidentiality? The choices made by social researchers in the context of law violation and harm. $J$ Acad Ethics. 2019 Jul:1-9. DOI: 10.1007/s10805-019-09336-2

\title{
Use of critical reflection as a research method: A case of research-induced distress?
}

\section{MALU MOHAN}

Keywords: Critical reflection, qualitative research, diary entries, professional distress, research-induced distress

\section{Introduction and context}

Critical reflection is widely used in qualitative research (1) It helps us understand participants' internal dialogues and analyse their thought processes. The use of oral or written reflections is a well-documented data collection method, particularly in educational research (2).

This case study presents the ethical distress of a public health researcher engaged in a study that sought to explore the preparedness of health professionals who had recently graduated from a particular branch of health services, to practise independently.

\section{The case}

The drastic commercialisation in this branch of medical education over the past three decades has resulted in a

Author: Malu Mohan (dr.malumohan@gmail.com), Research Coordinator Project on Decentralisation and Health: Lessons from the Kerala Experience, Kerala Institute of Local Administration, Thrissur, Kerala, INDIA.

To cite: Mohan M. Use of critical reflection as a research method - a case of research-induced distress? Indian J Med Ethics. 2020 Jan-Mar; 5(1) NS:19-20. DOI: 10.20529/IJME.2020.014.

OIndian Journal of Medical Ethics 2020. tremendous increase in the number of graduates and of private practices, and intensified competition in the private job market. This called for an enquiry into how prepared graduates were for these changes, and to provide quality care.

Recent graduates with independent practices were asked to record their daily clinical practice experiences for eight weeks in diary entries. They were asked to introspect on how their strengths and weaknesses as practitioners could have contributed to these experiences. They were also asked to identify those professional areas in which they considered themselves inadequately prepared for independent practice. Diary entries were to be reviewed at two weeks, with a second review along with face-to-face interviews at six weeks, and a third review at eight weeks. Apart from the time and effort that the participants had to invest, no other potential harm was anticipated from the study.

On preliminary review at two weeks, the researcher found that the diary entries were superficial, with hardly any reflection. She then impressed upon the participants the need for honest introspection and detailed recording.

After another four weeks, the researcher collected the diaries for analysis and found that the entries had become more detailed. In addition to reflections about daily clinical happenings, they included confessions of participants' insecurities as professionals responsible for the lives of other human beings, particularly because of the quality of their 
training. Most practitioners who had graduated from private institutions confessed that they had little experience in handling routine clinical situations. The patient inflow in many private colleges did not allow for adequate training in clinical procedures. Poor training had contributed to low confidence and subsequently to fear of practice.

Some diary entries described how they felt "inadequate and incompetent" as healthcare practitioners. The tone and language reflected disillusionment and dejection. In addition to emotional accounts of "not belonging" to the profession, there were conclusions such as "Maybe I am not suited for this profession" and "Joining this course was a huge mistake in life." The same emotional breakdowns, uncertainties and fears were expressed in face-to-face interviews.

My technical skills are poor. I didn't seen many cases in my college, since there was poor patient inflow there. Now I am paying money to the government to work here after graduation so I get to see more cases and improve my skills. I am trying, but I am not confident. I don't know if I am good enough. I mean, we are dealing with real human beings. I don't think I will survive in this field for long.

(Senior resident currently working in a public health facility)

\section{The researcher's distress}

In this study, reflection was used as a research method to explore participants' thought processes regarding their current performance as clinicians. The researcher's intention was to generate recommendations to improve the training and curriculum of this branch of medical education so that graduates would be better prepared to suit the demands of their profession. However, while making the diary entries, the participants developed certain views about their choices and training which they connected to their current performance. The reflections also indicated that the participants considered their training to be compromised in many areas. None of this had been anticipated by the researcher.
The researcher was distressed by some participants' selfdescriptions as "a failure", "incompetent", with "no future in the field". She was concerned that this would result in lasting damage to their lives and careers.

Some participants expressed their intention to leave the field in which they had trained, and pursue other interests. However, many had taken loans for this expensive training; they also had to face the expectations of their families and society. Hence at this stage in their lives, leaving their current profession and pursuing other options could have terrible personal consequences.

The researcher was also concerned about the possibility that if the graduates had not engaged in this exercise, they would have come to terms with their inadequacies over time, worked on them and emerged successful.

With two weeks left of the exercise, the researcher wondered if she should dissuade at least those participants who had responded strongly in their entries from continuing the reflection process. It was possible that the more time spent reflecting, the more convinced they would become of their own inadequacies.

\section{Questions raised by the case}

1. Can this be considered a case of research-induced harm?

2. Could the researcher have taken steps before and during the research to prevent the harm or reduce it?

3. What can the researcher do at this point to address the participants' feelings?

\section{References}

1. Morley C.Critical reflection as a research methodology. In:Liamputtong $\mathrm{P}$, Rumbold J, editors. Knowing differently: arts-based and collaborative research methods. New York: Nova Science Publishers, Inc; 2008. pp 26580.

2. Hewitt E. Building bridges: the use of reflective oral diaries as a qualitative research tool. International Journal of Research \& Method in Education. 2015 Nov; 40(4):1-15. Doi: 10.1080/1743727X.2015.1114601

\section{Using critical reflection in public health research: Identifying and mitigating emotional harms}

\section{VIJAYAPRASAD GOPICHANDRAN}

Author: Vijayaprasad Gopichandran (vijay.gopichandran@gmail.com), Assistant Professor, Department of Community Medicine, ESIC Medical College and PGIMSR, KK Nagar, Chennai 600078 INDIA.

To cite: Gopichandran V. Using critical reflection in public health research: identifying and mitigating emotional harms. Indian J Med Ethics. 2020 JanMar; 5(1) NS:20-1.DOI: 10.20529/IJME.2020.015.

Peer Reviewer: Manjulika Vaz

@Indian Journal of Medical Ethics 2020
Keywords: Critical reflection, mitigating harm, qualitative research, diary entries, professional distress, research-induced harm, anticipating research problems

Malu Mohan has described the distress faced by the researcher who attempted to study the practice preparedness of recent graduates of a stream of clinical practice through critically reflective diary entries (1). The graduates realised that they were grossly underprepared for competent and 